\title{
Eco-friendly Derivative UV Spectrophotometric Methods for Simultaneous Determination of Diclofenac Sodium and Moxifloxacin in Laboratory Mixed Ophthalmic Preparation
}

\author{
Muhammad Shahzad Chohan', Rafea Elamin Elgack Elgorashe ${ }^{2}$, Abdulmalek Ahmed Balgoname ${ }^{3}$, \\ Mahesh Attimarad ${ }^{3, *}$, Nagaraja SreeHarsha ${ }^{3}$, Katharigatta Narayanaswamy Venugopala ${ }^{3,4}$, \\ Anroop Balachandran Nair ${ }^{3}$, Shinu Pottathil ${ }^{1}$ \\ ${ }^{1}$ Department of Biomedical Sciences, College of Clinical Pharmacy, King Faisal University, Al-Hofuf, Al-Ahsa, SAUDI ARABIA. \\ ${ }^{2}$ Department of Chemistry, College of Science, King Faisal University, Al-Ahsa, SAUDI ARABIA. \\ ${ }^{3}$ Department of Pharmaceutical Sciences, College of Clinical Pharmacy, King Faisal University, Al-Hofuf, Al-Ahsa, SAUDI ARABIA. \\ ${ }^{4}$ Department of Biotechnology and Food Technology, Durban University of Technology, Durban, SOUTH AFRICA.
}

\begin{abstract}
Background: Diclofenac Sodium (DCL) and Moxifloxacin $\mathrm{HCl}(\mathrm{MOX}$ ) were simultaneously used after cataract surgery to reduce the post-operative inflammation and to control infection respectively. Objectives: Three simple, accurate, eco-friendly and reproducible UV spectroscopic methods were established for concurrent determination of diclofenac sodium and moxifloxacin in ophthalmic preparation without prior separation. Methods: The first technique was established on the measurement of a peak amplitude of the first derivative spectra at the zero-crossing wavelength of one analyte. The second method was the determination of peak amplitude difference between peak and trough of ratio spectra. The third method involves the measurement of the peak amplitude of the first derivative of ratio spectra. Water has been used as a solvent. Results: The analytes exhibited good linearity in the range of $1-15 \mu \mathrm{g} / \mathrm{mL}$ for $\mathrm{DCL}$ and $1-18 \mu \mathrm{g} / \mathrm{mL}$ for MOX with excellent correlation coefficient $\left(r^{2}>0.999\right)$. Low percent relative standard deviation confirmed the precision of the methods. Excellent recovery with low percent relative error proved the accuracy of the methods. The specificity of the methods was evaluated by analyzing the laboratory prepared solutions of DCL and MOX. Conclusion: Proposed three techniques were effectively utilized for the simultaneous determination of $\mathrm{DCL}$ and MOX from ophthalmic preparation. The outcomes of the proposed procedures were compared with the earlier described methods and no statistical difference was found between the methods in terms of accuracy and precision.
\end{abstract}

Key words: Diclofenac sodium, Moxifloxacin, Ophthalmic preparation, Ratio derivative spectroscopy, Validation.

\section{INTRODUCTION}

Cataract surgery has become more common in old age population both in rural and urban area. ${ }^{1}$ To avoid the post-operative cataract complications different topical preparations have been used, such as anti-inflammatory agents, antibiotics and anti-glaucoma preparations. To control the post-operative inflammation and to reduce the edema Non-steroidal anti-inflammatory drugs (NSAIDs) were preferred over steroidal preparation due to the safety. ${ }^{2}$ Further NSAIDs have similar efficacy as corticosteroids in controlling the pain, inflammation and formation of the blood-aqueous barrier after the cataract surgery. ${ }^{2,3}$ Several NSAIDs ophthalmic preparations are available in the market, however, diclofenac sodium (DCL Figure 1A) preparation is most widely
Submission Date: 16-07-2019; Revision Date: 26-09-2019; Accepted Date: 06-11-2019

DOI: 10.5530/ijper.54.1.20 Correspondence: Dr. Mahesh Attimarad, Associate Professor, Department of Pharmaceutical Sciences, College of Clinical Pharmacy, King Faisal University, Al-Hofuf, Al-Ahsa-31982, KINGDOM OF SAUDI ARABIA.

Phone: +966 553269799 E-mail: mattimarad@kfu. edu.sa

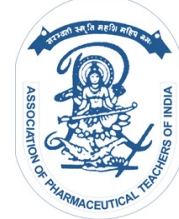

www.ijper.org 


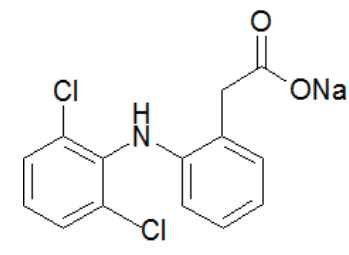

A

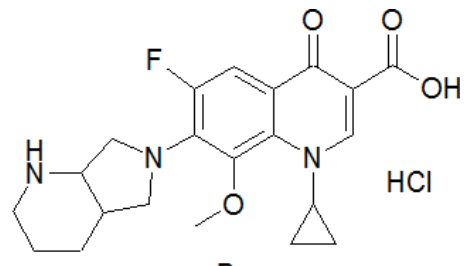

B
Figure 1: Chemical structure of Diclofenac sodium $(A)$ and Moxifloxacin $\mathrm{HCl}(B)$.

prescribed to control post-operative pain and inflammation. ${ }^{4}$ DCL act by inhibition of Cyclooxygenase (COX) enzyme thereby inhibiting the formation of prostaglandins, thereby reduce the pain and inflammation

Topical antibiotics are also applied after the cataract surgery as a prophylaxis to avoid post-operative infection. The fourth-generation fluoroquinolones, such as moxifloxacin $\mathrm{HCl}$ (MOX Figure 1B) has been preferred due to its broad-spectrum activity against Gram-positive and Gram-negative micro-organisms. Moxifloxacin acts as a bactericidal by inhibiting bacterial DNA gyrase and topoisomerase- $4 . .^{5-7}$ Hence, diclofenac sodium and moxifloxacin ophthalmic solutions are used simultaneously after the cataract surgery. Several analytical methods such as spectrophotometry, ${ }^{8-12}$ RP-HPLC $^{13-23}$ and electroanalytical methods ${ }^{24-26}$ were reported in the literature for the quantification of DCL and MOX alone or with other drugs. However, the simultaneous determination of DCL and MOX has not been reported. The objective of the current study was to establish a simple, economical, eco-friendly and precise derivative spectrophotometric procedure for concurrent estimation of DCL and MOX from laboratory mixed ophthalmic preparations.

\section{MATERIALS AND METHODS}

Pure samples of moxifloxacin (99.4\%) and diclofenac sodium $(99.5 \%)$ were purchased from the Sigma Aldrich (Germany), Moxifloxacin (0.5\%) and diclofenac sodium $(0.1 \%)$ ophthalmic preparations were procured from the local market. Methanol used to prepare primary standard stock solution was obtained from Sigma Aldrich (Germany). Distilled water prepared by Milli Q (Millipore, USA) water purifier was used throughout the experiments. Shimadzu UV-Vis spectrophotometer (1700) with $10 \mathrm{~mm}$ quartz cuvettes were used to record the UV absorption spectra. Absorption of solutions was measured at medium speed with a sampling interval of $0.1 \mathrm{~nm}$. The instrument has a fixed slit width of $1 \mathrm{~nm}$. Manipulation of absorption spectra and measurement of amplitude were carried out with the help of Shimadzu UV-probe (Version 2) software.

\section{Stock solutions of DCL and MOX}

Standard stock solutions of DCL and MOX were arranged by precisely weighed $100 \mathrm{mg}$ each and transferred into $10 \mathrm{~mL}$ measuring flask separately. Both the analytes were dissolved in methanol and the final volume was adjusted with methanol and stored in a refrigerator. Further, the working standard and laboratory mixed solutions were prepared by diluting stock solutions with water. Stock solutions were stable for two weeks in the refrigerator and working standard solutions were prepared daily.

\section{Procedure for construction of calibration curve}

Required amount of standard solutions of DCL and MOX were transferred into the $10 \mathrm{~mL}$ volumetric flasks to get the six solutions in the concentration range of $1-15 \mu \mathrm{g} / \mathrm{mL}$ of DCL and $1-18 \mu \mathrm{g} / \mathrm{mL}$ MOX separately. All these solutions were scanned in the range of $200-400 \mathrm{~nm}$ against water as blank and spectra were stored in the computer. Further, for the first derivative spectroscopic method, spectra were converted into first derivative spectra using $4 \mathrm{~nm}$ as $\Delta \lambda$ with scaling factor 10. The peak amplitude was measured at 216.2 $\mathrm{nm}$, the zero crossings for MOX, for quantification of DCL and similarly, the peak amplitude was measured at $276.1 \mathrm{~nm}$, the zero crossings for DCL, for quantification of MOX. Further, the calibration curves were created for both analytes by plotting a graph between peak amplitude against corresponding concentrations. In addition, regression equations were figured.

For ratio difference spectroscopic technique previously saved zero-order spectra of DCL $(1-15 \mu \mathrm{g} / \mathrm{mL})$ were divided by UV absorption spectrum of MOX $(4 \mu \mathrm{g} / \mathrm{mL})$ to get ratio spectra. Then the peak amplitude was measured at $338.6 \mathrm{~nm}$ and $303.7 \mathrm{~nm}$. The difference between these two amplitudes were calculated and the calibration curve was construed against the corresponding concentration of DCL. Similarly, zero-order spectra of MOX (1 $-18 \mu \mathrm{g} / \mathrm{mL})$ were divided by UV absorption spectrum of DCL $(3 \mu \mathrm{g} / \mathrm{mL})$ to get ratio spectra. Difference between the amplitudes at $265.5 \mathrm{~nm}$ and $246.2 \mathrm{~nm}$ was determined and the calibration curve was constructed against the corresponding concentration of MOX. Alternatively, regression equations were computed and used for the determination of the concentration of formulation and other solutions.

For ratio first derivative spectroscopic method, ratio spectra of DCL $(1-15 \mu \mathrm{g} / \mathrm{mL})$ were converted into first derivative spectra using $4 \mathrm{~nm}$ as $\Delta \lambda$ with scaling 
factor $1 \mathrm{~nm}$. The peak amplitude was measured at 259.0 $\mathrm{nm}$ and calibration curve was constructed against corresponding concentration. Similarly, ratio spectra of MOX $(1-18 \mu \mathrm{g} / \mathrm{mL})$ were converted into the first derivative spectra using $4 \mathrm{~nm}$ as $\Delta \lambda$ with scaling factor 1. Further, peak amplitude was measured at 333.6 $\mathrm{nm}$ and the calibration curve was constructed.

\section{Procedure for assay of laboratory prepared solutions}

Aliquot of standard solutions of DCL and MOX were transferred into $10 \mathrm{~mL}$ measuring flasks to get different ratio of both the analytes 1:5, 1:10, 1:18, 9:5, 9:10, 9:18, 15:5, 15:10, $15: 18 \mu \mathrm{g} / \mathrm{mL}$ respectively. Then the solutions were diluted with distilled water, absorption spectra were recorded and stored. Further, to determine the concentration of DCL and MOX from the mixture, spectra were converted into the first derivative, ratio spectra and the first derivative of ratio spectra according to the above-stated procedure. Further, peak amplitudes were measured at the respective wavelengths and concentration were determined using the relevant calibration curve or regression equations.

\section{Procedure for assay of sample solutions}

The sample solution was prepared by accurately transferring DCL and MOX ophthalmic solutions $(1 \mathrm{~mL}$ each) into $10 \mathrm{~mL}$ measuring flask. Then five $\mathrm{mL}$ methanol was added and the final volume was made with distilled water. Further, this solution was diluted with water to get the amount of DCL and MOX in the range of calibration curve. The sample solution was scanned in the range of $200 \mathrm{~nm}-400 \mathrm{~nm}$ and converted into the first derivative, ratio spectra and the first derivative of ratio spectra according to the above-mentioned procedure. Further concentration of DCL and MOX was determined from the calibration curves by all the methods.

\section{RESULTS AND DISCUSSION}

The over laid UV absorption spectra of DCL and MOX showed the complete overlap of spectra, (Figure 2) making it difficult to estimate simultaneously without prior separation. However, derivatization of spectra and measuring the peak amplitude at zero crossings of one of the analyte allow the quantification of one analyte in presence of another and formulation excipients a possible interfering components ${ }^{27-29}$ (Figure 3). Derivatization is a simple process, reliable, reproducible and shows good resolution of analytes from each other. Further, it reduces the signal to noise ratio and the use of scaling factor increases the sensitivity of the method.

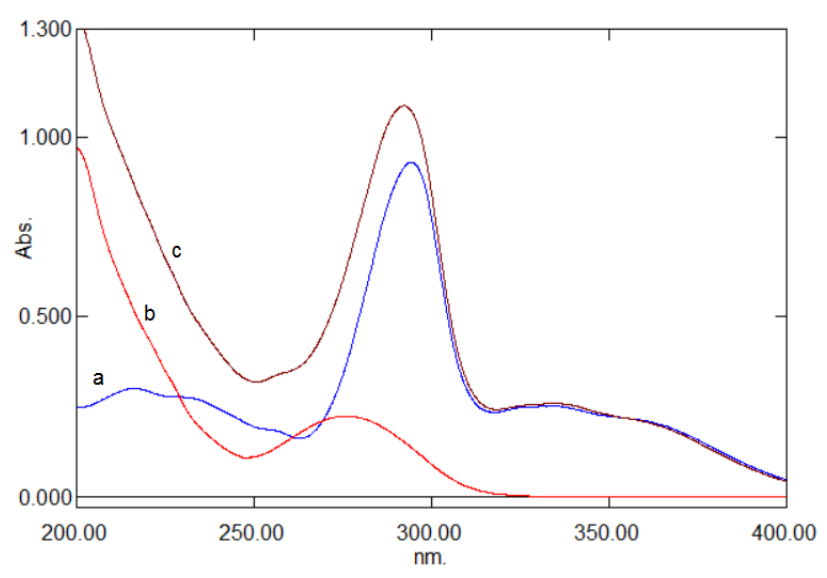

Figure 2: Over laid UV absorption spectra of MOX (a), DCL (b) and mixture of MOX and DCL (c).

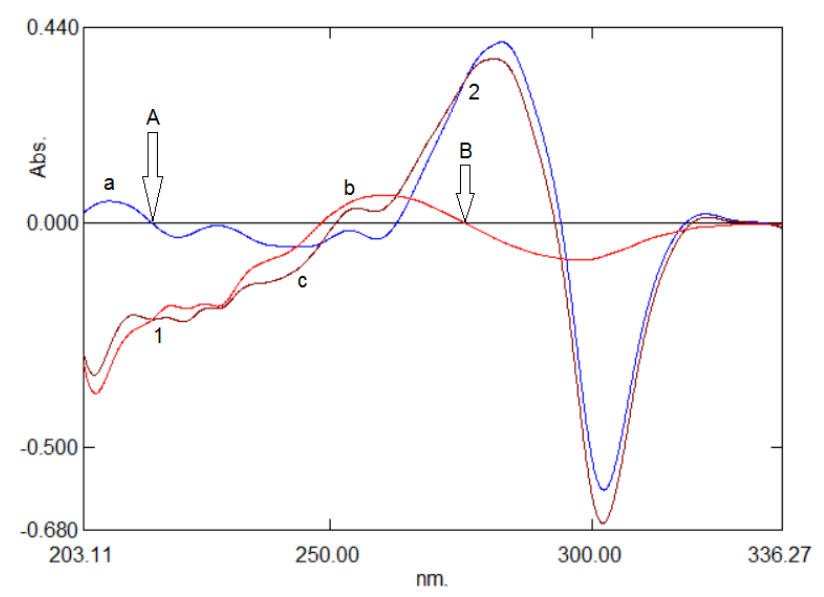

Figure 3: First derivative spectra of MOX (a), DCL (b) and mixture of MOX and DCL (c). Number 1 showing the same absorbace for DCL in stadrad and mixture at zero crossing for MOX (point A). Number 2 showing the same absorbace for MOX in standrad and mixture at zero crossing for DCL (point B).

In our study, a series of DCL and MOX solutions were converted into first derivative spectra separately (Figure 4A and 4B). Different wavelengths 2, 4, 6, 8 $\mathrm{nm}$ as $\Delta \lambda$ and different scaling factor from 10 to 100 were tried, however, $4 \mathrm{~nm}$ as $\Delta \lambda$ and scaling factor of 10 showed good resolution of analytes and appropriate signal to noise ratio. Hence all spectra were converted using $4 \mathrm{~nm}$ as $\Delta \lambda$ and scaling factor of 10 . The binary mixture of DCL and MOX was analyzed by measuring the peak amplitude at $216.6 \mathrm{~nm}$ for DCL, a zero-crossing point for MOX and at $276.1 \mathrm{~nm}$ for MOX, a zero crossing for DCL (Figure 3).

The second method was based on the amplitude difference between two wavelengths of ratio spectra, which eliminate the interference of another analyte. Generally, 

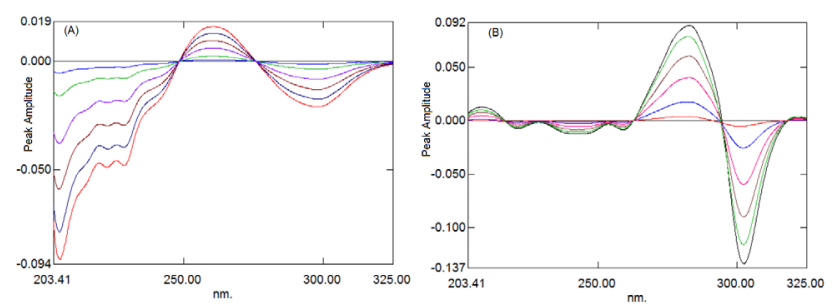

Figure 4: First derivative spectra of (A) DCL $(1,3,6,9,12$ and $15 \mu \mathrm{g} / \mathrm{mL})$ using $4 \mu \mathrm{g} / \mathrm{mL}$ MOX and (B) MOX $(1,4,8,12,16$ and $18 \mu \mathrm{g} / \mathrm{mL}$ ) using $3 \mu \mathrm{g} / \mathrm{mL}$ DCL.
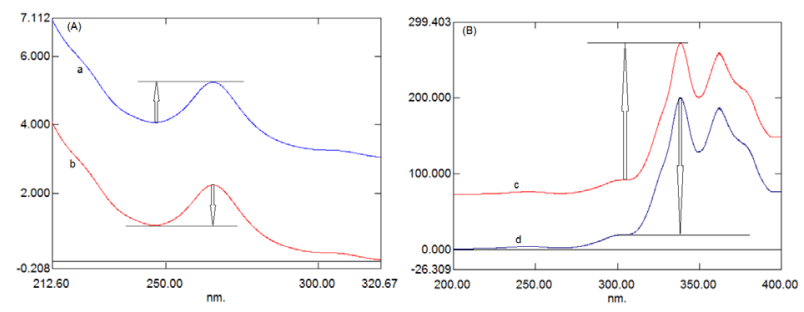

Figure 5: (A) Ratio spectra of DCL $6 \mu \mathrm{g} / \mathrm{mL}$ (a) and mixture (b) contating DCL $6 \mu \mathrm{g} / \mathrm{mL}$ and MOX $8 \mu \mathrm{g} / \mathrm{mL}$. B:Ratio spectra of MOX $8 \mu \mathrm{g} / \mathrm{mL}$ (c) and mixture (d) contating DCL $6 \mu \mathrm{g} / \mathrm{mL}$ and MOX $8 \mu \mathrm{g} / \mathrm{mL}$.

two wavelengths selected were corresponding to the peak and the trough, to get maximum sensitivity. It is clear from the Figure 5A and $5 \mathrm{~B}$ that the peak to trough difference of ratio spectra generated from the binary mixture and standard pure analyte remains same for the same amount of analyte, hence, the amplitude obtained by taking the difference between two selected wavelength is directly proportional to the concentration of the one analyte, without the interference from another. In our work, spectra of DCL in a range of $1-15 \mu \mathrm{g} / \mathrm{mL}$ were divided by the spectra of MOX $(4 \mu \mathrm{g} / \mathrm{mL})$ to generate ratio spectra of DCL (Figure 6A). Amplitude difference for DCL was determined by subtracting the trough amplitude at $303.7 \mathrm{~nm}$ from peak amplitude at $338.6 \mathrm{~nm}$ and plotted against the concentration of DCL to generate the calibration curve along with the regression equation. Similarly, a series of MOX spectra in the range of $1-18 \mu \mathrm{g} / \mathrm{mL}$ were converted into ratio spectra (Figure 6B) by dividing with DCL spectra $(3 \mu \mathrm{g} / \mathrm{mL})$. The two wavelengths selected were $265.5 \mathrm{~nm}$ of peak and 246.2 $\mathrm{nm}$ of a trough, the amplitude difference between these wavelengths was plotted against the concentration of MOX to generate the calibration curve along with the regression equation.

The third method was the first derivative of ratio spectra, an alternative to the amplitude difference. According to the Salinas proposal, ${ }^{29}$ the conversation of ratio spectra into derivative spectra will eliminate the interference from one of the analytes, allowing to
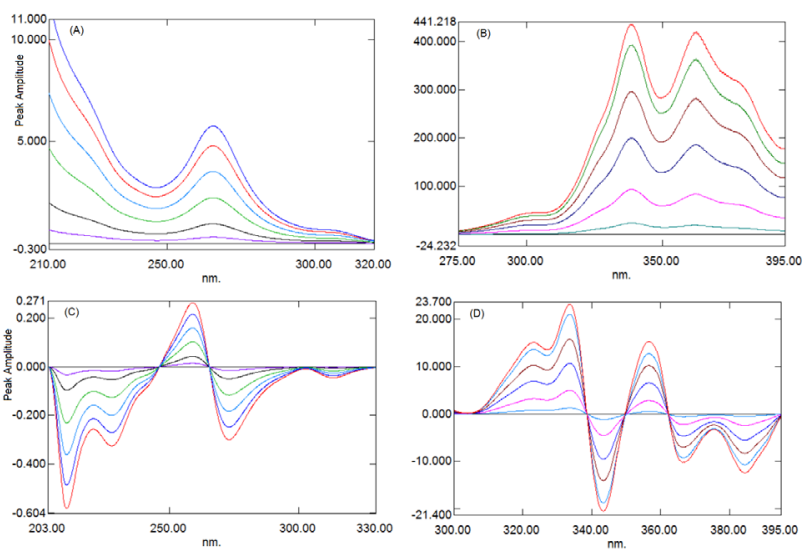

Figure 6: Ratio spectra of DCL $(1,3,6,9,12$ and $15 \mu \mathrm{g} / \mathrm{mL})$ using $4 \mu \mathrm{g} / \mathrm{mL}$ MOX and (B) ratio spectra of $\operatorname{MOX}(1,4,8,12$, 16 and $18 \mu \mathrm{g} / \mathrm{mL}$ ) using $3 \mu \mathrm{g} / \mathrm{mL}$ DCL. C. First derivative of ratio spectra of DCL. D. First derivative of ratio spectra of MOX.

determine the one component in the presence of another. Advantages of ratio derivative spectra are need not look for zero-crossing points and also give many maxima and minima to measure the amplitude, which is proportional to only one analyte. In our study, the above-generated ratio spectra of DCL were converted into the first derivative spectra using $4 \mathrm{~nm}$ as $\Delta \lambda$ with scaling factor 1. First derivative spectra of DCL (Figure 6C) showed one maximum at $259.0 \mathrm{~nm}$ and 4 minima at 313.4, 273.1, 227.7 and $210.2 \mathrm{~nm}$. However, peak amplitude and recovery percentage were better at $259.0 \mathrm{~nm}$ compared to other wavelengths. Similarly, the first derivative spectra of MOX were generated from the above-recorded ratio spectra of MOX (1 $-18 \mu \mathrm{g} / \mathrm{mL})$ using $4 \mathrm{~nm}$ as $\Delta \lambda$ with scaling factor 1 . First derivative spectra (Figure 6D) showed 3 maxima at 323.2333 .6 and $356.6 \mathrm{~nm}$ and three minima at 343.4, 366.8 and $385.1 \mathrm{~nm}$. However, $333.6 \mathrm{~nm}$ has been selected for analysis of MOX due to the better amplitude and recovery percentage. Amplitudes were measured at $259.0 \mathrm{~nm}$ for DCL and $333.6 \mathrm{~nm}$ for MOX and plotted against corresponding concentration to generate the calibration curve along with the regression equation.

\section{Validation of methods}

The proposed approaches were validated for linearity, sensitivity, selectivity, stability, accuracy and precision as per the requirements of $\mathrm{ICH}$, to prove that the proposed methods can be used for the intended purpose.

\section{Linearity}

The linearity of the suggested procedures was established by evaluating the six samples in the concentration range of $1-15 \mu \mathrm{g} / \mathrm{mL}$ for DCL and $1-18 \mu \mathrm{g} / \mathrm{mL}$ for 
MOX. For all the three methods amplitude determined were plotted against corresponding concentration to generate the calibration curves (Figure 7) along with regression equations. Table 1 , showed results of regression equations for both the analytes by all the three methods. It is evident from the correlation coefficient $\left(r^{2} \approx 1\right)$ that proposed analytical methods showed good linearity for both analytes. Further, the standard deviation of a slope, intercept and residuals were found to be low, confirming the good linearity of the methods.

\section{Sensitivity}

Limit of detection and limit of quantification were calculated to confirm the sensitivity of the method. LOD was determined by multiplying 3.3 with the ratio

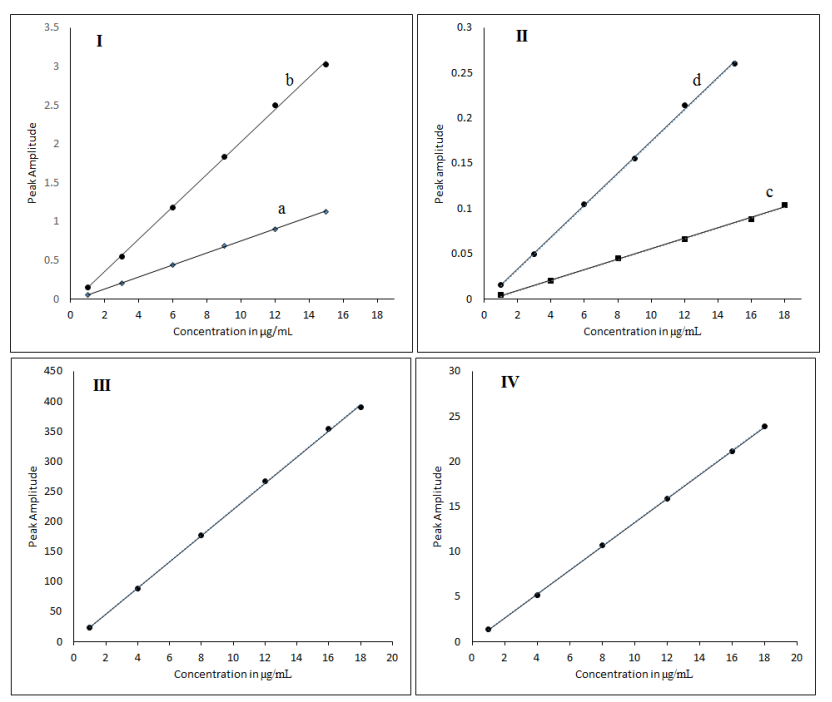

Figure 7: Calibration curves for First derivative method DCL (la) and MOX (IIC). Ratio difference Method DCL (Ib) and MOX (III) First derivative of Ratio method DCL (IId) and MOX (IV). of the standard deviation of intercept to the slope of the calibration curve. LOQ was determined by multiplying 10 with the ratio of the standard deviation of intercept to the slope of the calibration curve. The low LOD and LOQ showed in Table 1 indicated the good sensitivity of the proposed methods.

\section{Precision and accuracy}

Intra-day and inter-day accuracy and precision were determined by evaluating both analytes at three different concentration (low, medium and high) covering the entire calibration range. For intra-day, all these solutions were analyzed by proposed methods on the same day in triplicate $(n=3)$. For inter-day, same solutions were analyzed on three successive days in triplicate $(n=9)$. The precision was expressed as \%RSD (Table 2) and was found to less than 2 , indicating good precision of the procedures. Accuracy was expressed as the percentage relative error $(\% \mathrm{RE})$. The low $\% \mathrm{RE}$ indicated the accuracy of the suggested procedures.

\section{Recovery studies}

Recovery studies were executed at three diverse levels $(50 \%, 100 \%$ and $150 \%)$ to confirm the specificity and accuracy of the anticipated approaches by the standard addition method. To the previously analyzed formulation consisting of $1 \mu \mathrm{g} / \mathrm{mL}$ of DCL and $5 \mu \mathrm{g} / \mathrm{mL}$, of MOX, $0.5,1.0,1.5 \mu \mathrm{g} / \mathrm{mL}$ of DCL and $2.5,5,7.5 \mu \mathrm{g} / \mathrm{mL}$ of MOX were added separately. All these solutions were analyzed by proposed methods and peak amplitudes were determined. The concentration of the added amount of DCL and MOX were calculated using the regression equation and subtraction of initial formulation concentration. The good recovery of DCL and MOX from the formulation with low \%RSD (Table 3) confirmed the specificity and accuracy of the suggested

\begin{tabular}{|c|c|c|c|c|c|c|}
\hline \multirow{2}{*}{$\begin{array}{c}\text { Parameters } \\
\text { Drugs }\end{array}$} & \multicolumn{2}{|c|}{ First Derivative method } & \multicolumn{2}{|c|}{ Ratio difference method } & \multicolumn{2}{|c|}{ Ratio first Derivative method } \\
\hline & DCL & MOX & DCL & MOX & $\mathrm{DCL}$ & MOX \\
\hline Wave length [nm] & 216.2 & 276.1 & $\begin{array}{l}338.6 \\
303.7\end{array}$ & $\begin{array}{l}265.5 \\
246.2\end{array}$ & 259.0 & 333.6 \\
\hline Linearity Range $\left[\mu \mathrm{g} \mathrm{mL}^{-1}\right]$ & $1-15$ & $1-18$ & $1-15$ & $1-18$ & $1-15$ & $1-18$ \\
\hline $\operatorname{LOD}\left[\mu \mathrm{g} \mathrm{mL}^{-1}\right]$ & 0.31 & 0.12 & 0.06 & 0.09 & 0.22 & 0.08 \\
\hline $\mathrm{LOQ}\left[\mu \mathrm{g} \mathrm{mL}^{-1}\right]$ & 0.96 & 0.38 & 0.20 & 0.28 & 0.68 & 0.24 \\
\hline Slop [m] & 0.039 & 0.0408 & 0.2089 & 21.835 & 0.0182 & 1.3239 \\
\hline SD of slop & 0.0003 & 0.0001 & 0.0006 & 0.4486 & 0.00025 & 0.00704 \\
\hline Intercept [c] & -0.0172 & -0.0075 & -0.0644 & +1.4866 & -0.0052 & -0.0168 \\
\hline SD of Intercept & 0.00376 & 0.00157 & 0.0041 & 0.6167 & 0.00125 & 0.03305 \\
\hline Correlation Coefficient [r2] & 0.9994 & 0.9999 & 0.9992 & 0.9997 & 0.9994 & 0.9999 \\
\hline
\end{tabular}




\begin{tabular}{|c|c|c|c|c|c|c|c|}
\hline & \multirow[b]{2}{*}{$\begin{array}{l}\text { Amount of Drug } \\
{\left[\mu \mathrm{g} \mathrm{mL} \mathrm{L}^{-1}\right]}\end{array}$} & \multicolumn{2}{|l|}{ Inter-day } & \multirow[b]{2}{*}{$\%$ RE } & \multicolumn{2}{|c|}{ Intra-day } & \multirow[b]{2}{*}{$\%$ RE } \\
\hline & & $\begin{array}{l}\text { Amount found Mean } \\
{[n=3] \pm S D}\end{array}$ & $\%$ RSD & & $\begin{array}{c}\text { Amount found } \\
\text { Mean }[n=9] \pm S D\end{array}$ & \%RSD & \\
\hline \multicolumn{8}{|c|}{ First Derivative Method } \\
\hline \multirow{3}{*}{ DCL } & 1 & $0.98 \pm 0.01$ & 1.02 & -2.00 & $1.01 \pm 0.01$ & 0.99 & 1.00 \\
\hline & 9 & $8.87 \pm 0.14$ & 1.58 & -1.44 & $9.04 \pm 0.16$ & 1.77 & 0.44 \\
\hline & 15 & $15.16 \pm 0.28$ & 1.85 & 1.07 & $14.86 \pm 0.21$ & 1.41 & -0.93 \\
\hline \multirow{3}{*}{ MOX } & 1 & $1.02 \pm 0.01$ & 0.98 & 2.00 & $0.99 \pm 0.01$ & 1.01 & -1.00 \\
\hline & 10 & $10.02 \pm 0.08$ & 0.89 & 0.20 & $9.83 \pm 0.15$ & 1.53 & -1.70 \\
\hline & 18 & $17.75 \pm 0.16$ & 0.90 & -1.39 & $17.8 \pm 0.29$ & 1.63 & -1.11 \\
\hline \multicolumn{8}{|c|}{ Ratio difference method } \\
\hline \multirow{3}{*}{ DCL } & 1 & $0.99 \pm 0.01$ & 1.01 & -1.00 & $0.99 \pm 0.02$ & 2.02 & -1.00 \\
\hline & 9 & $9.05 \pm 0.16$ & 1.77 & 0.56 & $8.9 \pm 0.19$ & 2.13 & -1.11 \\
\hline & 15 & $14.83 \pm 0.27$ & 1.82 & -1.13 & $15.09 \pm 0.13$ & 0.86 & 0.60 \\
\hline \multirow{3}{*}{ MOX } & 1 & $0.98 \pm 0.01$ & 1.02 & -2.00 & $0.99 \pm 0.01$ & 1.01 & -1.00 \\
\hline & 10 & $9.95 \pm 0.08$ & 0.80 & -0.50 & $10.02 \pm 0.15$ & 1.50 & 0.20 \\
\hline & 18 & $18.07 \pm 0.22$ & 1.22 & 0.39 & $18.16 \pm 0.21$ & 1.16 & 0.89 \\
\hline \multicolumn{8}{|c|}{ Ratio first Derivative method } \\
\hline \multirow{3}{*}{ DCL } & 1 & $0.99 \pm 0.01$ & 1.01 & -1.00 & $1.02 \pm 0.01$ & 0.98 & 2.00 \\
\hline & 9 & $8.96 \pm 0.13$ & 1.45 & -0.44 & $9.05 \pm 0.03$ & 0.33 & 0.56 \\
\hline & 15 & $15.12 \pm 0.17$ & 1.12 & 0.80 & $14.85 \pm 0.17$ & 1.14 & -1.00 \\
\hline \multirow{3}{*}{ MOX } & 1 & $0.98 \pm 0.01$ & 1.02 & -2.00 & $0.99 \pm 0.01$ & 1.01 & -1.00 \\
\hline & 10 & $10.13 \pm 0.15$ & 1.48 & 1.30 & $9.93 \pm 0.11$ & 1.11 & -0.70 \\
\hline & 18 & $18.24 \pm 0.12$ & 0.66 & 1.33 & $17.8 \pm 0.26$ & 1.46 & -1.11 \\
\hline
\end{tabular}

SD: Standard deviation. \%RSD: Percent Relative Standard Deviation. \%RE: Percent Relative Error.

\begin{tabular}{|c|c|c|c|c|}
\hline & & $\begin{array}{c}\text { First } \\
\text { Derivative } \\
\text { method }\end{array}$ & $\begin{array}{c}\text { Ratio } \\
\text { difference } \\
\text { method }\end{array}$ & $\begin{array}{c}\text { Ratio first } \\
\text { Derivative } \\
\text { method }\end{array}$ \\
\hline & $\begin{array}{l}\text { Amount in } \\
{\left[\mu \mathrm{g} \mathrm{mL}^{-1}\right]}\end{array}$ & $\begin{array}{c}\% \\
\text { Recovery }\end{array}$ & $\begin{array}{c}\% \\
\text { Recovery }\end{array}$ & $\begin{array}{c}\% \\
\text { Recovery }\end{array}$ \\
\hline \multirow{5}{*}{$\begin{array}{c}\text { Recovery } \\
\text { of added } \\
\text { DCL }\end{array}$} & 0.5 & 99.71 & 100.19 & 99.42 \\
\hline & 1 & 99.39 & 98.76 & 100.29 \\
\hline & 1.5 & 100.49 & 101.09 & 99.45 \\
\hline & $\begin{array}{l}\text { Across } \\
\text { Mean }\end{array}$ & 99.86 & 100.01 & 99.72 \\
\hline & $\%$ RSD & 0.57 & 1.17 & 0.50 \\
\hline \multirow{5}{*}{$\begin{array}{c}\text { Recovery } \\
\text { of added } \\
\text { MOX }\end{array}$} & 2.5 & 98.83 & 100.46 & 99.04 \\
\hline & 5 & 100.66 & 99.87 & 98.16 \\
\hline & 7.5 & 99.51 & 99.39 & 100.23 \\
\hline & $\begin{array}{l}\text { Across } \\
\text { Mean }\end{array}$ & 99.67 & 99.91 & 99.14 \\
\hline & $\%$ RSD & 0.93 & 0.54 & 1.05 \\
\hline
\end{tabular}

approaches. Indicating the absence of interference from the formulation excipients during the analysis.

\section{Stability of solutions}

Stock solutions were stored in the refrigerator at $4^{\circ} \mathrm{C}$ and working standard solutions were prepared on a daily basis. Stock solutions in methanol and working solutions prepared in water were analyzed spectrophotometrically after storing at room temperate for five hours. Solutions did not show a significant difference in the assay results even after 15 days.

\section{Application of proposed methods}

\section{Assay of laboratory prepared solutions}

To study the applicability of the suggested procedures for the concurrent quantification of DCL and MOX, laboratory prepared solutions were analyzed. Different ratio of binary mixture DCL and MOX covering both above and below the normal level were prepared and analyzed by proposed methods. The good percent recovery and low \%RSD and \%RE error results (Table 4), indicated the excellent accuracy and precision of the methods and their power to analyze simultaneously DCL and MOX without prior separation, present even in different ratios. 
Table 4: Determination of DCL and MOX laboratory prepared mixtures using the proposed spectrophotometric methods

\begin{tabular}{|c|c|c|c|c|c|c|c|}
\hline \multirow{2}{*}{\multicolumn{2}{|c|}{$\begin{array}{c}\text { Amount taken } \\
\mu \mathrm{g} \mathrm{mL}-1\end{array}$}} & \multicolumn{6}{|c|}{ Percentage recovery } \\
\hline & & \multicolumn{2}{|c|}{ First Derivative method } & \multicolumn{2}{|c|}{ Ratio Difference method } & \multicolumn{2}{|c|}{ Ratio First derivative methoo } \\
\hline $\mathrm{DCL}$ & MOX & $\mathrm{DCL}$ & MOX & $\mathrm{DCL}$ & MOX & DCL & MOX \\
\hline 1 & 5 & 99.05 & 98.16 & 98.59 & 100.19 & 99.42 & 98.39 \\
\hline 1 & 15 & 98.59 & 100.93 & 100.43 & 98.56 & 99.06 & 99.26 \\
\hline 1 & 18 & 101.23 & 99.48 & 99.14 & 99.49 & 98.43 & 100.26 \\
\hline 9 & 5 & 99.05 & 99.07 & 100.17 & 100.59 & 100.24 & 100.49 \\
\hline 9 & 10 & 98.56 & 101.58 & 101.28 & 99.07 & 101.33 & 101.78 \\
\hline 9 & 15 & 100.94 & 99.44 & 99.09 & 98.44 & 98.73 & 98.41 \\
\hline 15 & 1 & 101.57 & 98.53 & 99.27 & 100.51 & 99.89 & 98.33 \\
\hline 15 & 10 & 98.51 & 99.07 & 99.93 & 99.83 & 100.46 & 99.29 \\
\hline 15 & 15 & 99.05 & 101.37 & 100.06 & 98.48 & 98.77 & 98.55 \\
\hline \multicolumn{2}{|c|}{ Mean } & 99.62 & 99.74 & 99.77 & 99.46 & 99.59 & 99.42 \\
\hline \multicolumn{2}{|c|}{ Mean \%RSD } & 1.26 & 1.25 & 0.83 & 0.87 & 0.96 & 1.21 \\
\hline
\end{tabular}

* \%RSD: Percent relative Standard deviation

Table 5: Determination of DCL and MOX opthalmic preparation mixtures using the proposed spectrophotometric methods and the reference methods

\begin{tabular}{|c|c|c|c|c|}
\hline & $\begin{array}{c}\text { First Derivative } \\
\text { method }\end{array}$ & $\begin{array}{l}\text { Ratio difference } \\
\text { method }\end{array}$ & $\begin{array}{c}\text { Ratio first } \\
\text { Derivative method }\end{array}$ & $\begin{array}{c}\text { Reference } \\
\text { Method }\end{array}$ \\
\hline & $\%$ Recovery & \% Recovery & $\%$ Recovery & $\%$ Recovery \\
\hline \multicolumn{5}{|c|}{ DCL } \\
\hline Mean & 99.61 & 98.86 & 99.65 & $99.76^{a}$ \\
\hline$\%$ RSD & 0.845 & 0.534 & 0.964 & 0.32 \\
\hline $\mathrm{n}$ & 6 & 6 & 6 & 6 \\
\hline Student $t$ - test ${ }^{c}$ & 0.781 & 0.826 & 0.846 & \\
\hline$F^{d}$ & 3.527 & 1.202 & 1.403 & \\
\hline \multicolumn{5}{|c|}{ MOX } \\
\hline Mean & 99.28 & 9.38 & 99.76 & $99.22^{b}$ \\
\hline$\%$ RSD & 0.594 & 1.116 & 0.486 & 1.276 \\
\hline $\mathrm{n}$ & 6 & 6 & 6 & 6 \\
\hline Student $t$ - test $(2.228)^{c}$ & 0.923 & 0.764 & 0.363 & \\
\hline$F(5.050)^{d}$ & 1.46 & 1.078 & 1.411 & \\
\hline
\end{tabular}

a HPLC method using Zorbax column (150mm, x $4.6 \mathrm{~mm}, 5 \mu \mathrm{m})$ and Mobile phase 20mM phosphate buffer (pH7)0.1\%TFA:acetonitrile (65:35) ${ }^{18}$

${ }^{b}$ HPLC Method using Zorbax column (150mm, x $4.6 \mathrm{~mm}, 5 \mu \mathrm{m}$ ) and Mobile phase 50mM phosphate buffer ( $\mathrm{pH}$ 5): methanol: acetonitrile (50:20:30) ${ }^{19}$

$c$ and $d$ are Critical values of $t$ and $F$ respectively at $p=0.05$

\section{Application to a real pharmaceutical preparation}

Proposed spectroscopic procedures were utilized for simultaneous quantification of DCL and MOX from ophthalmic preparation mixture. The results were tabulated in Table 5, in comparison with the reported HPLC method. The recovery results were inconsistent with the labeled amount, with low \%RSD, indicating the suitability of the suggested procedures for regular quality control of both DCL and MOX ophthalmic preparations. The statistical comparison of proposed and reported method showed low " $t$ " and " $F$ " value. Indicating no significant difference in the assay results of both methods in terms of accuracy and precision.

\section{CONCLUSION}

A simple, accurate and reproducible UV spectroscopic methods were established for concurrent quantification of DCL and MOX without the use of any sophisticated instrument or software. Water has been used as a solvent, making these methods economical and ecofriendly. Analysis of laboratory prepared mixture 
confirmed the accuracy, specificity and also absence of interference from formulation excipients. Further, statistical comparison with reported HPLC methods exhibited no statistical difference between the outcomes of proposed and reported methods in terms of accuracy and precision.

\section{ACKNOWLEDGEMENT}

The authors are thankful to the Deanship of Scientific Research, King Faisal University, Al-Ahsa for financial support under Nasher track (Grant No. 186187).

\section{CONFLICT OF INTEREST}

Authors have no conflict of interest.

\section{ABBREVIATIONS}

UV: Ultra violet; NSAIDs: Non-steroidal Anti-Inflammatory drugs; COX: cyclooxygenase; RP-HPLC: Reverse Phase High Performance Liquid Chromatography; \%RE: Percentage Relative Error; \%RSD: Percent Relative Standard Deviation; DNA: Deoxyribonucleic Acid; ICH: International Conference on Harmonisation; HCl: Hydrochloric acid; TFA: Trifluoro Acetic acid.

\section{REFERENCES}

1. Singh S, Pardhan S, Kulothungan V, Swaminathan G, Ravichandran JS, Ganesan S, et al. The prevalence and risk factors for cataract in rural and urban India. Indian J Ophthalmol. 2019;67(4):477-83.

2. Kessel L, Tendal B, Jørgensen KJ, Erngaard D, Flesner P, Andresen JL, et al. Post-cataract prevention of inflammation and macular edema by steroid and nonsteroidal anti-inflammatory eye drops. A systematic review. Ophthalmology. 2014;121(10):1915-24.

3. Hoffman RS, Braga-Mele R, Donaldson K, Emerick G, Hendresn B, Kahook $\mathrm{M}$, et al. Cataract surgery and nonsteroidal antiinflammatory drugs. J Cataract Refract Surg. 2016;42(9):1368-79. doi:10.1016/j.jcrs.2016.06.006

4. Bodaghi B, Weber ME, Arnoux YV, Jaulerry SD, LeHoang P, Colin J. Comparison of the efficacy and safety of two formulations of diclofenac sodium $0.1 \%$ eyedrops in controlling postoperative inflammation after cataract surgery. Eur J Ophthalmol. 2005;15(6):702-11.

5. Mark P, Randall O. Medication protocols for cataract surgery. Ophthalmology Times. 2013. https://www.ophthalmologytimes.com/cataract/medicationprotocols-cataract-surgery.

6. Mendoza-Schuster E, Cervantes-Coste G, Vanzzini V, Velasco-BaronaD C. Effect of Topical Moxifloxacin on the Bacterial Flora of the Ocular Surface following Cataract Surgery: A Randomized, Single-Masked Clinical Trial. Int J Ophthalmol Clin Res. 2018;5(2):1-6. doi.org/10.23937/2378-346X/1410088.

7. Silver LH, Woodside AM, Montgomery DB. Clinical safety of moxifloxacin ophthalmic solution $0.5 \%$ (Vigamox ${ }^{\circledR}$ ) in pediatric and nonpediatric patients with bacterial conjunctivitis. Surv Ophthalmol. 2005;50(Suppl 1):55-63.

8. Dsugi NFA, Elbashir AA. Supramolecular interaction of Moxifloxacin and _-cyclodextrin spectroscopic characterization and analytical application. Spectrochim. Acta A Mol Biomol Spectrosc. 2015;137:804-9.

9. Attimarad M, Al-Dhubiab BE, Alhaider IA, Nair AB, Sree HN, Mueen AK. Simultaneous determination of moxifloxacin and cefixime by first and ratio first derivative ultraviolet spectrophotometry. Chem Cent J. 2012;6:105-11.
10. Phaneemdra D, Nagamalleswari G. Quantitative Analysis of Paracetamol and Diclofenac in Combined Dosage Form by first Derivative and Simultaneous Equation Method in application to the determination of Dissolution Study. Int J Pharm Sci Res. 2012;3(10):3871-6.

11. Durga DHN, Lohithasu D, Murthy KVR. Development and Evaluation of Diclofenac sodium Controlled Release Dosage Forms Using Natural, Hydrophilic and Hydrophobic Polymers and its Comparative Studies. Indian J Pharm Edu Res. 2017;51(1):116-27.

12. Talele S, Nikam P, Ghosh B, Deore C. A Research Article on Nanogel as Topical Promising Drug Delivery for Diclofenac sodium. Indian J Pharm Edu Res. 2017;51(4s):s580-7.

13. Sahu PK, Panda J, Swain S. Chemometric Assisted Ion-Pair Chromatography of Metaxolone and Diclofenac in Binary Mixture: A Mechanistic Study. Indian J Pharm Edu Res. 2018;52(2):293-304.

14. Czyrski A, Sokół A, Szałek E. HPLC method for determination of moxifloxacin in plasma and its application in pharmacokinetic analysis. J Liq Chrom Relat Tech. 2017;40(1):8-12. DOI: 10.1080/10826076.2017.1280680

15. Heydari R, Shamsipur M, Naleini N. Simultaneous determination of EDTA, sorbic acid and diclofenac sodium in pharmaceutical preparations using highperformance liquid chromatography. AAPS Pharm Sci Tech. 2013;14(2):764-9. doi:10.1208/s12249-013-9962-0

16. Mohammad A, Momin M, Rangnekar B, Das SC. Development and validation of a RP-HPLC method for simultaneous quantification of bedaquiline (TMC207), moxifloxacin and pyrazinamide in a pharmaceutical powder formulation for inhalation. J Liq Chrom Relat Tech. 2018;41(8):415-21. DOI: 10.1080/10826076.2018.1437748

17. Reddy GPS, Navyasree KS, Jagadish PC, Bhat K. Analytical Method Development and Validation for HPLC-ECD Determination of Moxifloxacin in Marketed Formulations. Pharma Chem J. 2018;52(7):674-9. https://doi. org/10.1007/s11094-018-1879-1

18. Yilmaz B, Asci A, Palabiyik SS. HPLC Method for Determination of Diclofenac in Human Plasma and Its Application to a Pharmacokinetic Study in Turkey. J Chromatogr Sci. 2011;49(6):422-7.

19. Attimarad M, Chohan MS, Balgoname AA. Simultaneous Determination of Moxifloxacin and Flavoxate by RP-HPLC and Ecofriendly Derivative Spectrophotometry Methods in Formulations. Int J Environ Res Public Health. 2019;16(7):1196.

20. Jafari S, Hamidi S. Micro extraction techniques in antibiotic monitoring in body fluids: Recent trends and future. J Liq Chrom Relat Tech. 2018;41(7):401-7.

21. Sachdeva J, Sarangdevot YS, Kamble P. Simultaneous determination of Moxifloxacin hydrochloride and Flavoxate hydrochloride in a new tablet formulation. Int J Pharm Biol Sci. 2017;2:50-9.

22. Wichitnithad W, Kiatkumjorn $T$, Jithavech $P$, Thanawattanawanich $P$, Bhuket PR, Rojsitthisak P. A simple and sensitive HPLC-fluorescence method for the determination of moxifloxacin in human plasma and its application in a pharmacokinetic study. Pharmazie. 2018;73(11):625-9.

23. Khan FU, Nasir F, Iqbal Z, Khan I, Shahbaz N, Hassan M, Ullah F. Simultaneous determination of Moxifloxacin and Ofloxacin in physiological fluids using high performance liquid chromatography with ultraviolet detection. J Chromatogr B Analyt Technol Biomed Life Sci. 2016;1017:120-8.

24. Hamdan II. Capillary electrophoresis in the analysis of pharmaceuticals in environmental water: A critical review. J Liq Chrom Relat Tech. 2017;40(3):11125. DOI: 10.1080/10826076.2017.1293550

25. Hussien EM, Derar AR. Selective Determination of Diclofenac and Clomiphene with a Single Planar Solid-State Potentiometric Ion Selective Electrode. J Electrochem Soc. 2019;166(10):B780-6.

26. Yilmaz B, Ciltas U. Determination of diclofenac in pharmaceutical preparations by voltammetry and gas chromatography methods. J Pharm Anal. 2015;5(3):153-60.

27. Patel KN, Patel JK, Rajput GC, Rajgor NB. Derivative spectrometry method for chemical analysis: A review. Der Pharm Lett. 2010;2(2):139-50.

28. Kamal AH, El-Malla SF, Hammad SF. A Review on UV spectrophotometric methods for simultaneous multicomponent analysis. Eur J Pharm Med Res. 2016;3(2):348-60.

29. Salinas F, Nevado BJ, Mansilla EA. A new spectrophotometric method for quantitative multicomponent analysis resolution of mixtures of salicylic and salicyluric acids. Talanta. 1990;37(3):347-51. 
PICTORIAL ABSTRACT

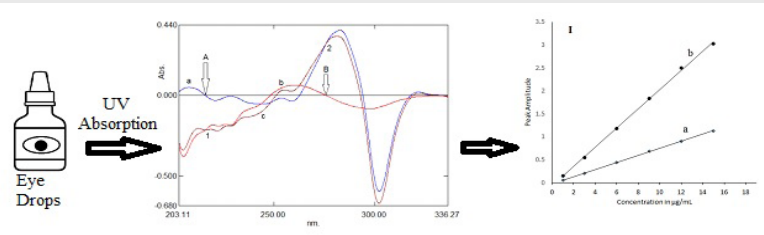

\section{About Authors}

Dr. Muhammad Shahzad Chohan completed graduation from Nishtar Medical College, Multan, Pakistan and post-graduation from University of Health Sciences, Lahore, Pakistan in the specialization of Anatomy. Currently, he is involved in teaching Anatomy and Histology, Physical Assessment and First Aid in College of Clinical Pharmacy, KFU. He can work well in dynamic team-oriented environment. He is aggressive to learn and work with new technologies.

His major research interest has been histological observations of herbicide in the tissues of liver, spleen and adrenal glands. Recently his interest shifted towards the development of analytical methods. He attended the national and international conferences, workshops and seminars. He has also published national and international publications in reputed journals.

\section{SUMMARY}

The objective of the current work was to develop a simple, economical and eco-friendly UV spectroscopic methods for simultaneous determination of diclofenac sodium and moxifloxacin from eye drops. Three different spectroscopic methods were established by manipulation of UV spectra. The first technique was established on the measurement of a peak amplitude of the first derivative spectra at the zero-crossing wavelength of one analyte. The second method was the determination of peak amplitude difference between peak and trough of ratio spectra. The third method involves the measurement of the peak amplitude of the first derivative of ratio spectra. Water has been used as a solvent. All three methods were validated according to the $\mathrm{ICH}$ guidelines. Further, proposed methods were efficiently applied for the simultaneous estimation of both analyses from ophthalmic preparations.

Cite this article: Chohan MS, Elgorashe REE, Balgoname AA, Attimarad M, SreeHarsha N, Venugopala KN, et al. Eco-friendly Derivative UV Spectrophotometric Methods for Simultaneous Determination of Diclofenac Sodium and Moxifloxacin in Laboratory Mixed Ophthalmic Preparation. Indian J of Pharmaceutical Education and Research. 2020;54(1):166-74. 